\title{
Technology of Planning of Blended Learning
}

\section{Babakhodjaeva Lobar Gafurdjanovna}

Associate Professor of Westminster International University in Tashkent, Independent Researcher of Chirchik State Pedagogical Institute in Tashkent, Uzbekistan.

Article History: Received:11 January 2021; Accepted: 27 February 2021; Published online: 5 April 2021

ABSTRACT: This article discusses the technologies of organizing mixed type lessons. In particular, there was a description of the technology of mixed lessons, their types, methods of use. This article also reveals the features, technical and important aspects of the materials used in mixed education that distinguish them from ordinary lessons.

Key words: technology, mixed education, classroom, school, materials, scientific, blended learning.

\section{INTRODUCTION}

The blended course consists of activities and knowledge assessment that span the local and online environment. Since most of the study time is spent on the Internet, the online environment should consist of intuitive navigation that immediately engages students in relevant, contextualized activities. The online environment also provides an excellent way to provide clear and understandable information to students that sets expectations and guides course learning.

\section{MATERIALS}

A reverse engineering process can be followed to prototype a lesson in your LMS or course on a website. A prototype of one lesson can then serve as a model for all other lessons in the course.

\section{Figure 1. The process of reverse engineering a blended lesson.}

It is understood that each subject has its own place in the learning system. Subjects are only available to

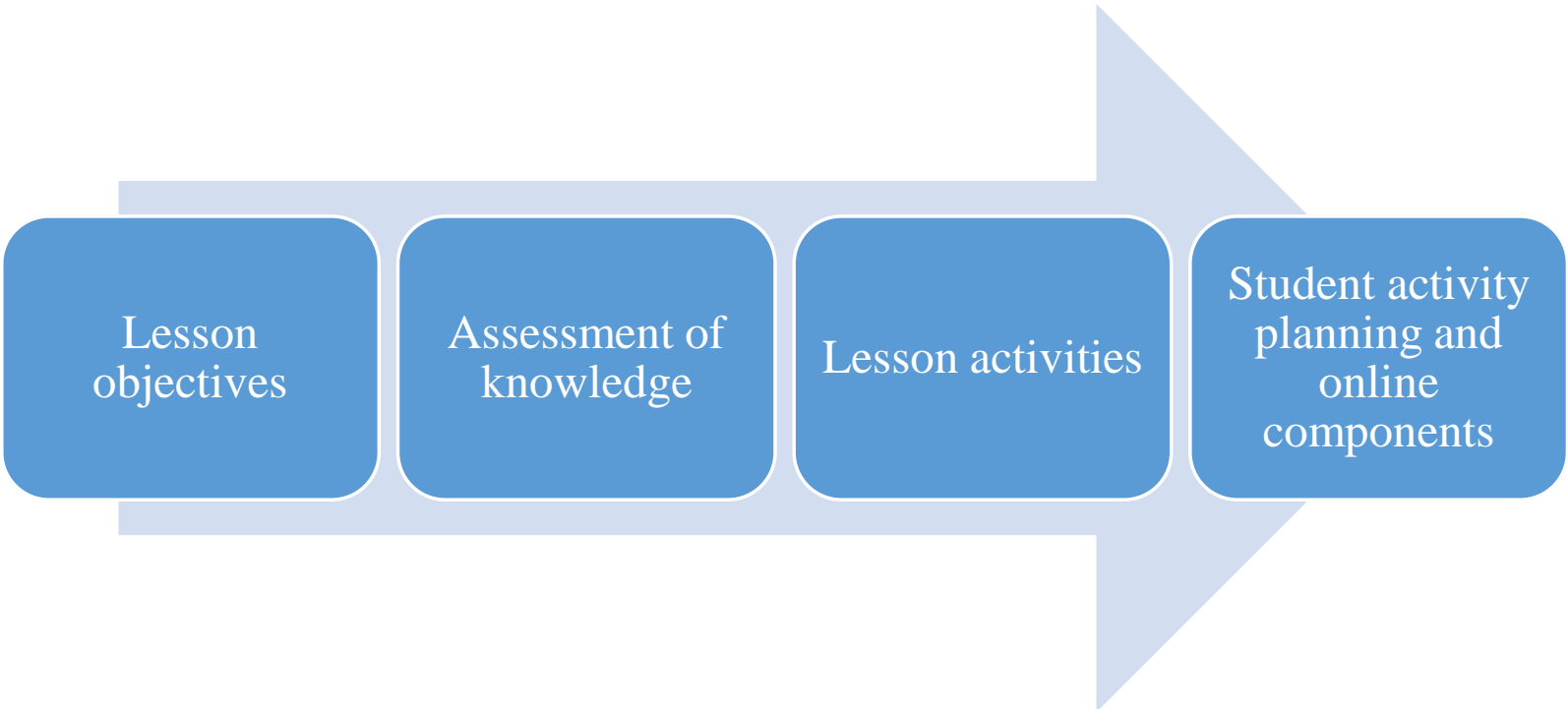

students enrolled in these subjects, and each lesson has its own link to the required materials and links. Each lesson should begin with an introduction explaining the structure and sequence of activities. The introductory lesson page follows:

- Attract students' attention with a story or example that gives real meaning to the desired learning outcomes.

- Develop students' thinking by asking questions or setting specific tasks to complete.

- Identify the necessary tasks for the lesson, indicating the sequential order of activities on the topic.

- Indicate which lesson objectives will be performed on site and which online.

- Link to the next lesson assignment.

- Link so you can return to the course home page. 


\section{Working with hyperlinks}

Hyperlinks are what the Internet does. They add dimension to information by connecting web pages to other pages or websites that are linked. In a blended course, hyperlinks allow students to easily navigate from one part of the course to another, or simply see how one activity relates to past or future lessons. It is recommended that you use appropriate hyperlinks that support navigation on your blended course site.

Some LMSs make it easy to link to other parts of the course website by providing an index of course topics and actions that you can click to select. Some web page editors allow you to copy and paste or drag and drop links or web pages right into the content. It doesn't require any web programming knowledge.

Herbic (2009) emphasizes that there should be "Strong integration between the [blended course] components: weekly topics or course content pointing to discussion, teacher feedback on progress, classroom practice."

Figure 2. An example of the use of hyperlinks in the instructions for the lesson.

\section{Lesson Objectives}

Before starting this week's lesson, you need to:

1. Introduce yourself at the Acquaintance discussion forum (on the Internet).

2. Register in the group Trip (Internet)

Then, to successfully complete this tutorial, you should:

1. Read and study Chapters 1 and 2 of our textbook.

2. Take test 1

3. Participate in peer learning activities in the class

4. Join your group members on the tour

5. Post the results of your trip to the Week 1 Discussion (Internet).

Then organize these lesson components in order. Allocation by activity is a common mistake, as it does not promote linear progress and, in fact, can impede student progress in the lesson. The components should be organized in a logical order.

Why does a student visit the subject page? This is invariably for performing tasks such as:

- View reviews or ratings

- Work on learning activities.

- Complete knowledge assessment activities.

The blended course home page should guide students to whatever tasks are most relevant to them at the time they attend. For example, the home page might include:

- Complete course schedule or complete list of lessons, with hyperlinks to activities and coursework assignments.

- Information only about the current lesson

- Checklist of regular weekly tasks, including in class

-A dynamic list of recent activities in the course (for example, new discussions or feedback).

\section{Ease of use from start to finish}

Since we want students to spend their time learning and not navigating the course website or having trouble with online tools, it is important that the course website materials are designed to be user-friendly. This is not easy for any course designer because we inherently understand our own design and therefore it is usually easy for us. But it's not easy for everyone, especially for beginners.

A key convenience principle is to keep things as short and as simple as possible. As usability expert Steve Krug (2006) says, "Don't make me think." This mantra is especially relevant for course websites because we want students to spend their time thinking about the subject, not the interface.

You don't have to be a usability expert to design with usability in mind. Two simple practices will help you design a comfortable learning experience: 
Imagine your hardest student is working through a course or lesson website. Will he know where to go without hesitation? Will it always be clear what he should do next?

Have a few people test the site. Try to use students, friends, or family members rather than colleagues who are already subject matter experts or have teaching experience. You can look over their shoulders, but don't help them drive - just ask them to find their way through a lesson or two and write down anything that will delay them or make no sense.

Plan to make changes to the design of your course website, or even the instruction manual, based on the feedback you receive from others.

\section{Technical support}

Be sure to describe how students can get technical assistance. This is very important in any course that is highly technology dependent. You can refer to the university's technical support line. If this is not possible, you may have to prepare to deal with technical issues. If you do, make it easier for yourself: (1) by providing a set of links to online guides or guides for using the LMS or website; and (2) creating a "Students Helping Students" or "Questions and Answers" discussion forum where students are encouraged to post messages and answer technical questions related to the course.

As an educator, it's a good idea to have your own tech support plan, too. You don't want to get stuck in an LMS with no idea who to contact.

Methods

Since the experience of each blended course may be different, providing an overview or walkthrough of a typical lesson in the program helps students anticipate normal workflow and expectations.

The lesson review should:

- Explain how audience and online activities are related.

- Describe what the students will do each week or lesson.

- Explain how one lesson relates to other lessons.

The overview can be just text, as in this example, but it can also be done as a video screencast that shows how students move through the course and explains how and when the various activities and lessons are intertwined.

How this course works: one week $=$ one lesson

In this blended course, each lesson lasts a full week, starting every Tuesday and ending the following Monday at 11:59 pm.

We meet face to face in the classroom every Thursday. During these meetings, we will discuss complex topics of the lesson and work out the individual tasks of the project. I will not lecture, but I will lead each of you to actively participate in every meeting.

The rest of the course activities take place online, either jointly, or by yourself. On the course website, these sessions are detailed in lessons. Each lesson requires:

1. Readings and videos with a short self-assessment. Study these resources before each Thursday meeting.

2. A test that examines the lesson material and allows multiple attempts. Complete each test online before your Thursday meeting.

3. A project that allows you to apply the knowledge gained during the lesson through genuine practice. Begin each project before meeting on Thursday. Submit each project to the Online Discussion Forum by 11:59 pm on Monday.

4. A project discussion forum where you: (1) share your project; and (2) provide feedback on your colleague's projects. Participate in discussions throughout the week. Completing tests and participating in project discussions prior to classroom meetings every week is mandatory.

5. The course ends with a comprehensive final examination and a final final project.

In addition to an overview of a typical lesson, the blended course syllabus contains a description of each regular lesson and an assessment by type (for example, "Online Discussion" or "Self-study"). These descriptions help explain what students should generally expect both online and locally. These should include when, where and how assignments should be graded - online or in class. These descriptions should also explain how something done in the audience relates to activities performed on the Internet, and vice versa.

Your expectations from student participation

Be clear about your expectations for student participation - whether interacting with materials on the site, communicating with group members, or participating in a class or discussion. This is very important because 
blended courses require students to have more autonomy and more control over the learning process in their free time. Students should be prepared to develop habits that will make them successful week after week, in a more relaxed rhythm of the mixed course.

Explain to students that the mixed course should be as much work as the traditional course. Also, describe in as much detail as possible how much time students should spend on each type of activity in each lesson. You can describe the waiting time in your lesson overview in the program, as well as on the lesson introduction page.

\section{Example of expectations for planning students' time on the course:}

\section{Students should plan to spend 9-12 hours per week on this course. This will vary from week}

to week, but a typical week might include:

Lesson introduction (online): $<1$ hour.

Reading (online, text): 2-3 hours.

Watching online lectures and presentations (online): $<2$ hours.

Study and test on the passed material (online): $<1$ hour.

Classroom (face to face): 2 hours.

Lab or assignment (online, onsite): 2-3 hours.

\section{RESULTS}

Your expectations from students are described by the objectives and outcomes of the course and its lessons, as well as general statements that you can include in the program. But expectations are also set by the grading framework, which represents the student's progress over the course. The rating scheme can be a percentage, numeric scale, or letter rating.

Percentage is the most common basis for grading.

Example of a scheme for assessing knowledge on a subject.

\begin{tabular}{|l|l|}
\hline Category & Percentage \\
\hline Participation & 15 \\
\hline Tests & 15 \\
\hline Projects & 40 \\
\hline Exam & 30 \\
\hline Total & 100 \\
\hline
\end{tabular}

\section{DISCUSSION}

In a blended course, you may find it easier to evaluate things that you would not be able to measure in a faceto-face course. For example, a blended course may be required both on-site and online. Online participation is recorded by the course website and can be quantified in terms of quantity and quality. This may allow you to more confidently place more emphasis on something like class participation if it is an important part of student success. Other elements, such as tests, may be less important in a blended course if you turn them into an online selfassessment format.

\section{CONCLUSION}

The blended course relies on an online environment that is both thorough and easy to use. The course home page should serve as a focal point, helping students immediately immerse themselves in relevant activity lessons. Lessons should clearly guide students along the learning path - both online and in the classroom. Hyperlinks should be used wisely, making navigation between important subject and lesson elements easier without distracting students with uncritical content. The focus of students on learning objectives is supported by the ease of design. Teachers should focus on the student experience when designing and organizing lessons on the course site and should test usability by requesting feedback from others.

The last part of this reverse design model for blended courses is curriculum building. The blended program goes beyond basic course information to include a detailed timetable with hyperlinks, an overview or walkthrough of a typical lesson, class descriptions, student expectations, and a grading scheme weighted around the revised course grading system. 
A blended course planning program checklist is provided below:

- Lessons are presented with stories, case studies, questions, or problems to grab students' attention and make the results meaningful.

- An introduction and summary are provided at the beginning of each lesson

- Instructions and requirements are presented in a simple, understandable, and logical manner.

- The writing style is clear, concise and direct.

- Numbers are used to indicate successive steps in a task or process.

- The materials constantly indicate when knowledge is assessed - traditionally or online.

- Link to online activities and link to traditional events and vice versa.

- Provides direct links to course materials and resources.

- Content items are presented in a logical sequence.

- The course website is designed to guide students towards the course objectives.

- The course website provides easy navigation for the student.

- The course website has been tested by non-experts to help identify any major usability issues.

- Curriculum including contact information, outline, requirements and guidelines are available from the outset.

- The curriculum guides students towards the classroom workflow by providing a descriptive overview or step-by-step guidance for a typical lesson.

- Contact information for consultants and technical support is provided in the program.

- All assessed activities are listed in advance in the program.

- The procedure for submitting assessment items is clear.

- The curriculum informs students about their expectations for participation.

- Students know when and how they will receive feedback from the teacher.

- Assessment criteria are set out in the course syllabus and within the assignment or activity itself.

- The link between the graded items is clear.

\section{REFERENCES}

1. Amaral, K. E., \& Shank, J. D. (2010). Enhancing student learning and retention with blended learning class guides. Educause Quarterly,33(4), n4.

2. Aycock, A., Garnham, C., \& Kaleta, R. (2002). Lessons learned from the hybrid course project. Teaching with Technology Today, 8(6).

3. Gerbic, P. (2009). Including online discussions within campus-based students' learning environments. In E. Stacey \& P. Gerbic (Eds.), Effective blended learning practices: Evidence-based perspectives in ICT-facilitated education (pp. 21-38). Hershey, NH: Information Science Reference.

4. Grigorovici, D., Nam, S., \& Russill, C. (2003). The effects of online syllabus interactivity on students' perception of the course and instructor. Internet and higher education, 6(1), 41-52.

5. Krug, S. (2006). Don't make me think! A common sense approach to web usability (2nd Ed.). Upper Saddle River, NJ: New Riders.

6. McGee, P., \& Reis, A. (2012). Blended course design: A synthesis ofbest practices. Journal of Asynchronous Learning Networks, 16(4),7-22.

7. Niederhauser, D., Reynolds, R., Salmen, D., \& Skolmoski, P. (2000). Theinfluence of cognitive load on learning from hypertext. Journal ofEducational Computing Research, 23(3), 237-255.

8. Ross, B., \& Gage, K. (2006). Global Perspectives on Blended Learning. The handbook of blended learning: Global perspectives, localdesigns, 155.

9. 9.Lothridge, Karen; et al. (2013). "Blended learning: efficient, timely, and cost effective". Journal of Forensic Sciences. 45 (4): 407-416. doi:10.1080/00450618.2013.767375.

10. 10.Moskal, Patsy; Dziuban, Charles; Hartman, Jole (December 20, 2012). "Blended learning: A dangerous idea?". Internet and Higher Education. 18: 15-23. doi:10.1016/j.iheduc.2012.12.001.

11. 11.Oliver M, Trigwell K (2005). "Can 'Blended Learning' Be Redeemed?".E-Learning. 2 (1): 17-26. doi:10.2304/elea.2005.2.1.17.

12. 12.Graham, Charles R.; Woodfield, Wendy; Harrison, J. Buckley (2013-07-01). "A framework for institutional adoption and implementation of blended learning in higher education". The Internet and Higher Education. Blended Learning in Higher Education: Policy and Implementation Issues. 18: 4-14. doi:10.1016/j.iheduc.2012.09.003. ISSN 1096-7516. 
13. 13.Siemens, G., Gašević, D., \& Dawson, S. (2015). Preparing for the Digital University: a review of the history and current state of distance, blended, and online learning. Pg. 62. Athabasca University. Retrieved from http://linkresearchlab.org/PreparingDigitalUniversity.pdf 